\title{
Respiratory muscle activity during rapid eye movement (REM) sleep in patients with chronic obstructive pulmonary disease
}

\author{
J E S White, M J Drinnan, A J Smithson, C J Griffiths, G J Gibson
}

\begin{abstract}
Background - In patients with chronic obstructive pulmonary disease (COPD) periods of hypopnoea occur during rapid eye movement (REM) sleep, but the mechanisms involved are not clear.

Methods - Ten patients with stable COPD were studied during nocturnal sleep. Detailed measurements were made of surface electromyographic (EMG) activity of several respiratory muscle groups and the accompanying chest wall motion using magnetometers.

Results - Hypopnoea occurred in association with eye movements during phasic rapid eye movement (pREM) sleep. During pREM sleep there were reductions in EMG activity of the intercostal, diaphragm, and upper airway muscles compared with non-REM sleep. Episodic hypopnoea due to partial upper airway occlusion ("obstructive" hypopnoea) was seen consistently in four subjects while the others showed the pattern of "central" hypopnoea accompanied by an overall reduction in inspiratory muscle activity. Although activity of the intercostal muscles was reduced relatively more than that of the diaphragm, lateral rib cage paradox (Hoover's sign) was less obvious during pREM-related hypopnoea than during wakefulness or non-REM sleep.

Conclusions - Hypopnoea during REM sleep in patients with COPD is associated with reduced inspiratory muscle activity. The pattern of hypopnoea may be either "obstructive" or "central" and is generally consistent within an individual. Relatively unopposed action of the diaphragm on the rib cage during REM sleep is not accompanied by greater lateral inspiratory paradox.

(Thorax 1995;50:376-382)
\end{abstract}

Keywords: REM sleep, chronic obstructive pulmonary disease, respiratory muscle activity, hypopnoea.

Ventilation during rapid eye movement (REM) sleep is characterised by its variability both within and between subjects. ${ }^{12}$ In patients with chronic obstructive pulmonary disease (COPD) periods of hypopnoea in REM sleep result in hypoxaemia, but the precise mechanisms are uncertain. In healthy subjects reduced respiratory muscle activity has been shown in REM sleep ${ }^{3-5}$; this is generally most marked in those respiratory muscles which also have a postural function, with activity of the $s$ diaphragm being relatively spared or even in- $\overrightarrow{0}$ creasing. Patients with airways obstruction due $\overrightarrow{-}$ to $\mathrm{COPD},{ }^{6-8}$ have been reported to show a $\stackrel{\omega}{\sigma}$ similar pattern during REM sleep, but the results have been variable and the numbers of patients studied in detail are few.

One potential consequence of discoordinate $\stackrel{p}{\dot{\omega}}$ inspiratory muscle action is recurrent upper $\sigma$ airway narrowing or occlusion. Although early 은 work on nocturnal hypoxaemia in patients with $\rightarrow$ COPD suggested that obstructive apnoea was $\frac{7}{0}$ frequently present, ${ }^{9}$ the population studied was highly selected and later work appeared to $\vec{\theta}$ refute this conclusion. ${ }^{10}$ It has subsequently of been shown, however, that the clinical features associated with the obstructive sleep apnoea syndrome can be seen with obstructive hypopnoea rather than complete apnoea. ${ }^{11}$ In patients with COPD it is not clear to what extent diminished activity of the upper airway $\overrightarrow{\vec{B}}$ muscles in REM sleep may result in obstructive hypopnoea and consequent arterial desaturation.

Many patients with COPD, airways obstruction, and hyperinflation have abnormal rib cage motion when awake. In particular, a commonly recognised feature is inspiratory paradox of the lateral rib cage margin (Hoover's sign) due to indrawing by a flattened diaphragm. ${ }^{12}$ We postulated that, in such patients, relative sparing of the activity of the diaphragm during REM sleep with suppression of the other respiratory muscles might further impair rib cage motion and therefore exacerbate oxygen 0 desaturation.

We studied a group of patients with COPD N to elucidate further the patterns of respiratory muscle activity in REM sleep and the ways in 0 which these may result in hypopnoea.

\section{Methods}

Ten men with severe COPD and mild to moderate hypoxaemia were studied (table 1). They $\stackrel{\unrhd}{\unrhd}$ were middle aged or elderly and of normal $\bar{r}$ build, and all but one had hyperinflation (de- $\delta$ fined as increased functional residual capacity). None was a regular heavy drinker and all ab- 흘 stained from alcohol for 24 hours before the study. Four subjects (nos 1-4) showed obvious lateral rib cage paradox (Hoover's sign) when examined in the semi-recumbent posture while awake. All subjects gave informed consent prior to participation in the study which was approved by the local ethics committee. 
Table 1 Subject characteristics, pulmonary function and daytime arterial blood gas tensions

\begin{tabular}{|c|c|c|c|c|c|c|c|c|c|}
\hline $\begin{array}{l}\text { Patient } \\
\text { no. }\end{array}$ & $\begin{array}{l}\text { Age } \\
\text { (years) }\end{array}$ & $\begin{array}{l}B M I \\
\left(\mathrm{~kg} / \mathrm{m}^{2}\right)\end{array}$ & $\begin{array}{l}\text { Motion } \\
\text { awake }\end{array}$ & $\begin{array}{l}F E V_{1} \\
\text { (\% predicted) }\end{array}$ & $\begin{array}{l}F R C \\
\text { (\% predicted) }\end{array}$ & $\begin{array}{l}R V \\
\text { (\% predicted) }\end{array}$ & $\begin{array}{l}\mathrm{PaO}_{2} \\
(\mathrm{kPa})\end{array}$ & $\begin{array}{l}\mathrm{PaCO}_{2} \\
(\mathrm{kPa})\end{array}$ & $\begin{array}{l}\mathrm{SaO}_{2} \\
(\%)\end{array}$ \\
\hline $\begin{array}{c}1 \\
2 \\
3 \\
4 \\
5 \\
6 \\
7 \\
8 \\
9 \\
10 \\
\text { Mean }\end{array}$ & $\begin{array}{l}53 \\
76 \\
69 \\
69 \\
60 \\
61 \\
74 \\
48 \\
53 \\
70 \\
63\end{array}$ & $\begin{array}{l}19 \cdot 5 \\
23 \cdot 5 \\
28 \cdot 0 \\
19 \cdot 9 \\
21 \cdot 8 \\
24 \cdot 5 \\
21 \cdot 5 \\
19 \cdot 2 \\
17 \cdot 9 \\
18 \cdot 0 \\
21 \cdot 4\end{array}$ & $\begin{array}{l}\text { LP } \\
\text { LP } \\
\text { LP } \\
\text { LP } \\
\text { Normal } \\
\text { Normal } \\
\text { Normal } \\
\text { Normal } \\
\text { Normal } \\
\text { Normal }\end{array}$ & $\begin{array}{r}8 \\
24 \\
30 \\
23 \\
27 \\
46 \\
41 \\
11 \\
10 \\
18 \\
24\end{array}$ & $\begin{array}{l}243 \\
172 \\
197 \\
210 \\
236 \\
137 \\
106 \\
243 \\
279 \\
275 \\
210\end{array}$ & $\begin{array}{l}277 \\
260 \\
222 \\
240 \\
294 \\
202 \\
309 \\
309 \\
384 \\
111 \\
261\end{array}$ & $\begin{array}{r}8 \cdot 3 \\
8 \cdot 8 \\
7 \cdot 2 \\
8 \cdot 1 \\
10 \cdot 9 \\
12 \cdot 2 \\
7 \cdot 9 \\
9 \cdot 0 \\
7 \cdot 9 \\
8 \cdot 9\end{array}$ & $\begin{array}{l}5 \cdot 4 \\
6 \cdot 1 \\
6 \cdot 2 \\
6 \cdot 1 \\
5 \cdot 4 \\
2 \cdot 5 \\
7 \cdot 7 \\
5 \cdot 6 \\
4 \cdot 5 \\
5 \cdot 5\end{array}$ & $\begin{array}{l}91 \\
93 \\
87 \\
90 \\
94 \\
90 \\
95 \\
89 \\
94 \\
91 \\
91 \cdot 4\end{array}$ \\
\hline
\end{tabular}

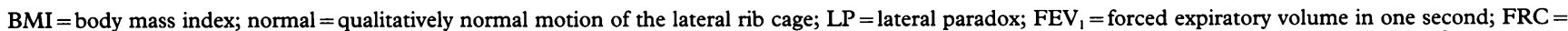
functional residual capacity; $\mathrm{RV}=$ residual volume; $\mathrm{PaO}_{2}=$ arterial partial pressure of oxygen; $\mathrm{PaCO}_{2}=$ arterial partial pressure of carbon dioxide; $\mathrm{SaO} \mathrm{O}_{2}=$ oxygen saturation.

Standard sleep study signals were recorded throughout a night in hospital following one acclimatisation night. Arterial oxygen saturation $\left(\mathrm{SaO}_{2}\right)$ was recorded by a pulse oximeter using a finger probe (Biox 3700e, Ohmeda, Louisville, USA), and airflow by thermistors at the mouth and nose (Oxford Medical, Oxford, UK). Posteroanterior (RCPA) and lateral (RCLAT) rib cage motion and posteroanterior abdominal motion (ABPA) were obtained using pairs of magnetometers. ${ }^{13}$ Transmitter magnetometers were positioned in the midline over the xiphisternum and just above the umbilicus for RCPA and ABPA, respectively, and over the left lower costal margin in the mid axillary line for RCLAT; receiver magnetometers were positioned at the same horizontal level on the back or in the mid axillary line. A single channel electroencephalogram (EEG) $\mathrm{C}_{z} / \mathrm{O}_{z}$ was recorded and an electrooculogram (EOG) from left and right eyes was combined as a single channel as previously validated. ${ }^{14}$ In addition, for the purpose of the present study, surface electromyographic (EMG) activity was recorded from selected respiratory muscles using $9 \mathrm{~mm}$ diameter silver/silver chloride cup electrodes (SLE, Croydon, Surrey, UK) applied to carefully cleaned and abraded skin with an impedance of less than $1 \mathrm{k} \Omega$. Electrodes were placed at least $2 \mathrm{~cm}$ apart over five groups of respiratory muscles: (1) the "genioglossus group" $\left(E M G_{G e}\right)$, placed $1 \mathrm{~cm}$ to each side of the midline midway between the chin and the hyoid bone; (2) the parasternal intercostal $\left(\mathrm{EMG}_{\mathrm{Int}}\right)$ muscles lateral to the sternum in the second intercostal space; (3) the diaphragm $\left(E M G_{D_{i}}\right)$ in the seventh or eighth intercostal space in the anterior axillary line, on the right to reduce cardiac artefact; (4) the rectus abdominis $\left(\mathrm{EMG}_{\mathrm{RA}}\right)$ muscle $2 \mathrm{~cm}$ lateral to the umbilicus; and the external oblique $\left(E M G_{\mathrm{ExOb}}\right)$ muscle midway between the inferior costal margin and the iliac crest in the mid clavicular line. Signals were amplified, filtered at $40-1000 \mathrm{~Hz}$, rectified, and integrated using a first order low pass filter with a time constant of $50 \mathrm{~ms}$. Both integrated and "raw" EMG data were recorded on digital tape (EDR 128, Earthdata, Southampton, UK). The posture of the subject was recorded with a low light camera (Panasonic, Japan) and an infrared light using a three hour VHS videotape (NV-G18 Panasonic, Japan) running at half normal speed to give a study duration of six hours. Synchronisation was achieved by superimposition of waveforms on the video image and by placing a clock in view of the camera. ${ }^{15}$ The subject was allowed to adopt his preferred posture and left to sleep in the darkened room.

Epochs of wakefulness, non-REM and REM sleep, as assessed by standard criteria after Rechtschaffen and Kales, ${ }^{16}$ were identified from a hard copy of the whole study replayed using a chart recorder (TA4000 Gould, Ilford, UK). REM sleep was further divided into phasic (pREM) and tonic (tREM) periods depending on the presence or absence of eye movements using a method similar to that described by Wiegand et al. ${ }^{5}$ Only periods of sleep with stable signals and with the subject in his preferred sleeping posture were analysed. Sixteen such periods of REM sleep were identified (range per subject 1-3), together with 29 adjacent periods of non-REM sleep (range per subject 1-4). The data from these periods were transferred to a personal computer using an analogue to digital converter (Dash-16, Metrabyte, Taunton, MA, USA). The periods analysed included mean (SD) numbers of consecutive breaths of 59 (23) and 64 (18) during nonREM and REM sleep, respectively. The analysis was performed using specifically developed software which calculated the peak level of integrated EMG activity above electrical zero, recorded from each muscle for each breath and for the captured section as a whole. ${ }^{17}$ Results of peak EMG activity in each individual were expressed as ratios between REM and non-REM sleep. Apnoea was defined as cessation of airflow and hypopnoea as a reduction in rib cage excursion of at least $50 \%$, both for at least 10 seconds. Apnoeas or hypopnoeas were classified as "obstructive" when (1) rib cage motion in the posteroanterior dimension was paradoxical relative to abdominal motion, and (2) a large increase was seen in $E M G_{G e}$ at the termination of the event, together with EEG evidence of arousal. Events were defined as "central" when there was an overall decrease in muscle activity accompanied neither by posteroanterior paradox nor snoring.

Statistical comparisons of the magnitude of EMG activity were performed by paired $t$ test after logarithmic transformation of the ratios of activity in REM and non-REM sleep.

\section{Results}

The subjects generally slept poorly with mean (SD) sleep efficiency of 45 (20)\%. All subjects 


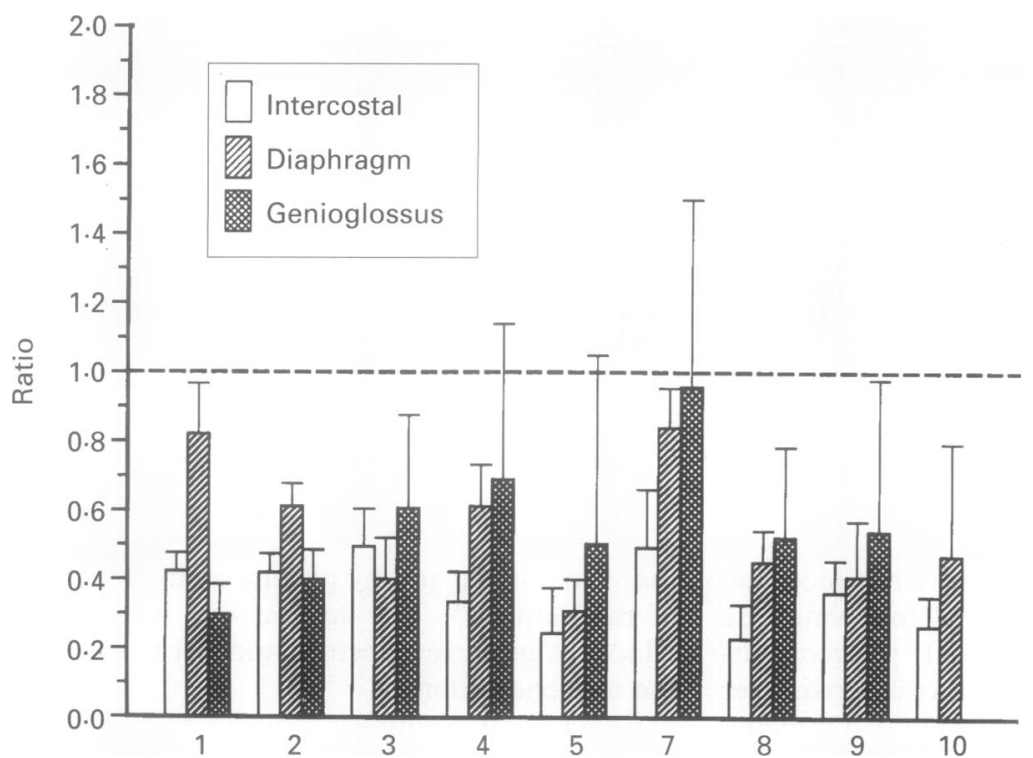

Figure 1 Mean (SD) ratios of peak EMG activity during phasic REM and non-REM sleep recorded from intercostal, diaphragm, and genioglossus muscle groups in nine subjects (subject no. 6 had no pREM sleep). The reductions in intercostal and diaphragmatic activity in $p R E M$ sleep were significant $(p<0.002$ and $p<0.001$, respectively) and intercostal activity was more reduced than that of the diaphragm $(p<0.02)$. No satisfactory recordings of $E M G_{G e}$ were obtained from subject no. 10 in REM sleep. had at least one epoch of REM sleep but no periods of phasic eye movements were observed in one subject (no. 10).

No attempt was made to measure levels of tonic EMG activity. Phasic inspiratory $\mathrm{EMG}_{\text {Int }}$ and $E M G_{D i}$ activity was seen in all stages of wakefulness and sleep. Phasic EMG $\mathrm{Ge}_{\text {activity }}$ was usually detectable during wakefulness, although in some subjects this was obscured by high levels of tonic activity. Phasic EMG $\mathrm{Ee}_{\mathrm{Ge}}$ activity was seen in all subjects during sleep. The magnitude of mean peak inspiratory EMG activity during tREM sleep was similar to that during non-REM sleep for $E M G_{G e}$ and $E M G_{D i}$, while peak $E M G_{\text {Int }}$ activity was less in tREM than in non-REM sleep ( $p<0 \cdot 05$, table 2$)$. During pREM sleep peak activity of all three muscle groups was markedly suppressed compared with non-REM sleep (table 2 ). The proportional reduction in $\mathrm{EMG}_{\mathrm{Int}}$ activity in $\mathrm{pREM}$ sleep was significantly greater than that of $E M G_{D i}\left(p<0.02\right.$, fig 1). $E M G_{I n t}$ and $E M G_{D i}$ activity were both significantly more reduced in pREM than in tREM sleep ( $p<0.001$, table 2). $E M G_{G e}$ activity during pREM sleep was also significantly suppressed in comparison with non-REM sleep $(\mathrm{p}<0 \cdot 002)$.

Figure 2 shows an example of the reduction in $\mathrm{EMG}_{\mathrm{Int}}$ activity associated with phasic eye movements in a subject with qualitatively normal rib cage motion and fig 3 shows a similar pattern in a subject who had paradoxical lateral rib cage motion both when awake and asleep. The episodes of reduced EMG activity illustrated in figs 2 and 3 fit the criteria for "central" hypopnoeas. REM-related hypopnoeas of this type were seen in five of the nine subjects (nos 2, 5, 7, 8, and 10) in whom pREM sleep was recorded.

Table 2 Mean (SD) ratios of EMG activity during

\begin{tabular}{llll}
\hline Ratio & $G e$ & Int & $D i$ \\
\hline tREM/non-REM & $1 \cdot 08(0 \cdot 8)$ & $0.69(0.3) *$ & $0.86(0.3)$ \\
pREM/non-REM & $0.56(0 \cdot 2) \dagger$ & $0.36(0 \cdot 1) \ddagger$ & $0.55(0 \cdot 2) \ddagger$ \\
Difference between & NS & $\mathrm{p}<0.01$ & $\mathrm{p}<0.005$ \\
tREM and pREM & & &
\end{tabular}

$\mathrm{Ge}=$ genioglossus; Int $=$ intercostal; $\mathrm{Di}=$ diaphragm muscles; NS $=$ not significant

$* \mathrm{p}<0.05$ different from unity.

$t \mathrm{p}<0.002$ different from unity.

$\ddagger \mathrm{p}<0.001$ different from unity.

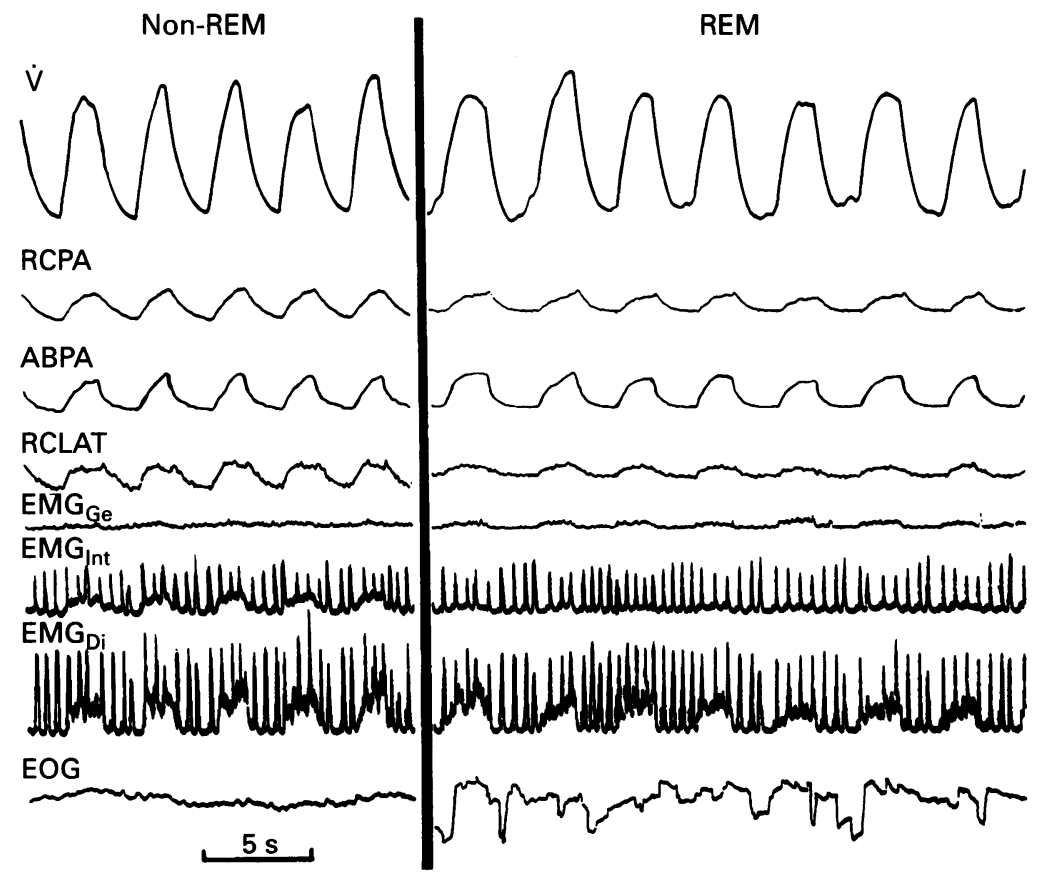

Figure 2 Recordings from subject no. 7 with normal lateral rib cage motion during non-REM and pREM sleep. The recordings are in order from the top: airflow ( $V$ ); posteroanterior rib cage motion (RCPA); posteroanterior abdominal motion ( $A B P A)$; lateral rib cage motion (RCLAT); genioglossus group EMG (EMG $\left.G_{G}\right)$; intercostal EMG $\left(E M G_{I n}\right)$; diaphragmatic EMG (EMG $G_{D i}$ ); electrooculogram (EOG). Note considerably reduced intercostal activity and slightly reduced diaphragmatic activity in association with phasic eye movements during REM sleep compared with non-REM reduced. 


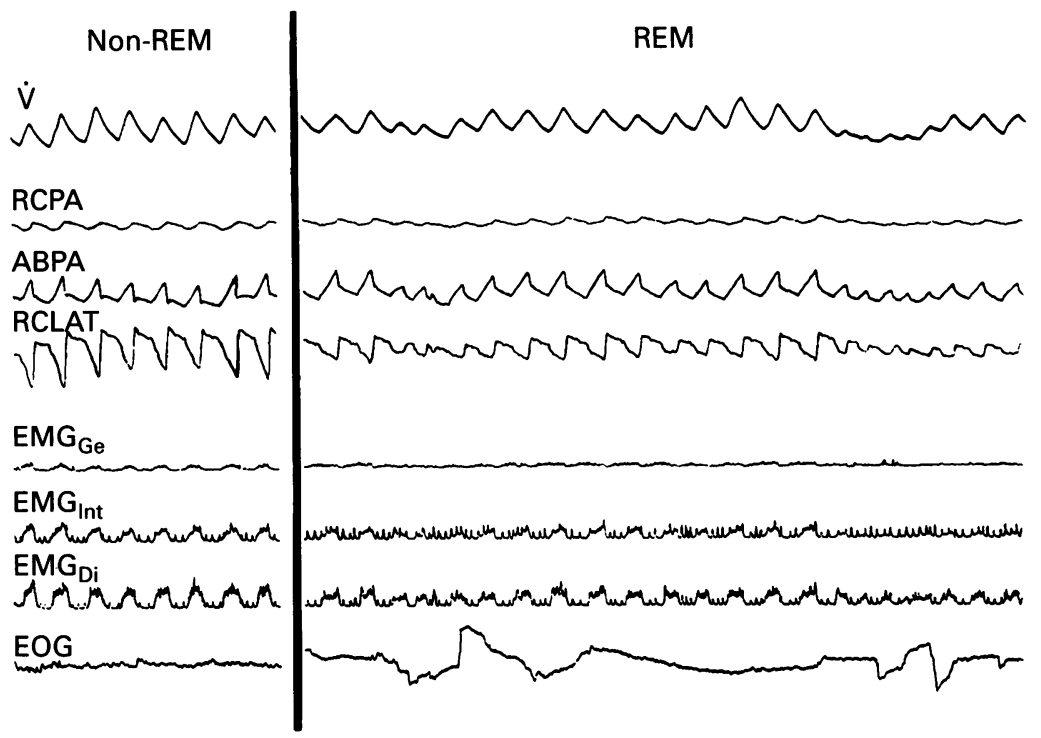

Figure 3 Recordings from subject no. 2 with paradoxical lateral rib cage motion (Hoover's sign) during non-REM and REM sleep. Signals and time scale as in fig 2. Note reduced activity of all inspiratory muscles in association with two bursts of phasic eye movements during REM sleep compared with non-REM sleep.

None of the six subjects with qualitatively normal rib cage motion while awake developed lateral paradox during sleep. Furthermore, none of the subjects with lateral rib cage paradox when awake showed an exaggeration of this pattern in REM sleep. In general, less inspiratory muscle activity was associated with less paradox (fig 3).

Three subjects (nos 1, 3, and 9) had repeated episodes of "obstructive" hypopnoea associated with paradoxical movement of the rib cage and abdomen in the posteroanterior dimension. All three were snorers. A fourth subject (no. 4) showed a similar pattern of muscle activity with a large burst of $\mathrm{EMG}_{\mathrm{Ge}}$ activity at the termination of hypopnoea, but without detectable posteroanterior paradox. Since the hypopnoeas in this subject were again associated with snoring, they were also classified as obstructive. None of the other subjects snored. Of the obstructive hypopnoeas recorded during REM sleep $88 \%$ occurred in association with eye movements - that is, pREM. The example in fig 4 is noteworthy in that this subject (no. 1) had "obstructive" hypopnoea during pREM sleep and also showed Hoover's sign which was present during wakefulness and non-REM sleep; the latter disappeared transiently with the development of posteroanterior abdominothoracic paradox during periods of hypopnoea.

The type of hypopnoea ("central" or "obstructive") observed during REM sleep was consistent within an individual. The number of such hypopnoeas recorded in each subject varied between 9 and 25 with a mean (SD) of $16 \cdot 3(6 \cdot 8)$. Of these events $68 \%$ were associated with desaturation of $\geqslant 4 \%$.

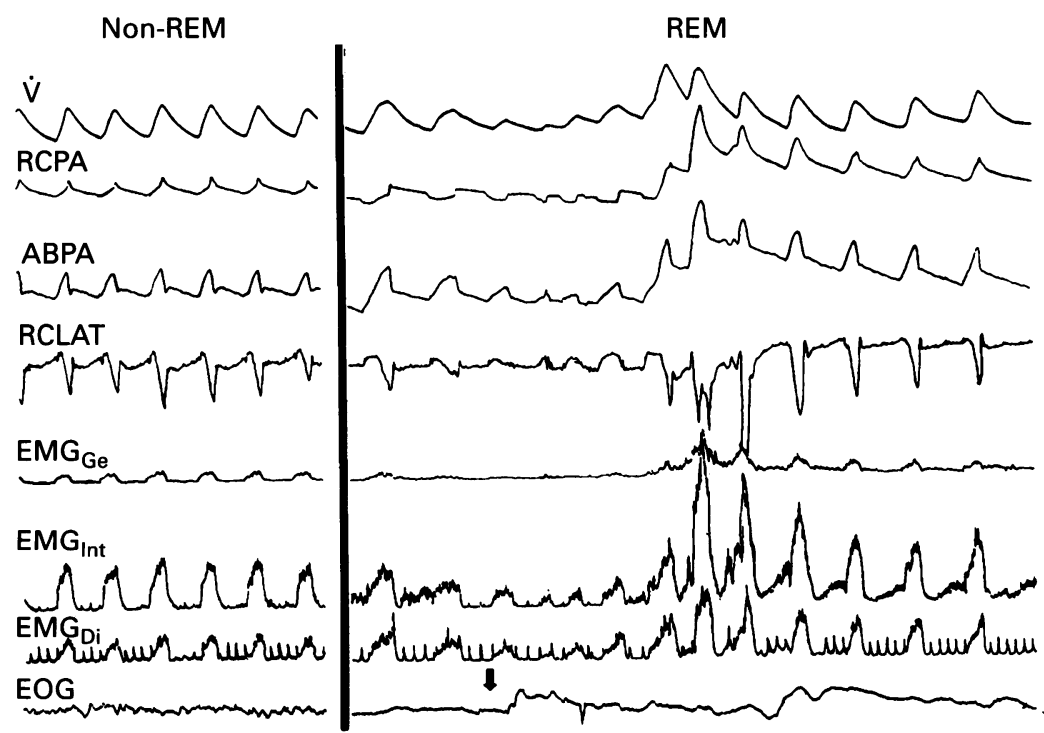

Figure 4 Recordings from subject no. 1. Signals and time scale as in fig 2. Note hypopnoea in association with reduced inspiratory muscle activity at the onset of eye movements (arrowed) in REM sleep compared with non-REM sleep. $A$ change in RCPA motion to a paradoxical pattern is seen, indicating an obstructive event. At the same time RCLAT motion becomes more normal with paradoxical motion returning after the hypopnoea. 
Expiratory abdominal muscle activity (predominantly in $\mathrm{EMG}_{\mathrm{ExOb}}$ ) was recorded in the awake state in only two individuals and in none was such activity detected during sleep.

\section{Discussion}

Ventilation during REM sleep shows considerable variation within and between individuals and this is reflected in the different results of published studies. Such variation follows largely from the variability of REM sleep itself, which is not a homogeneous state but consists of two distinct subtypes: so-called phasic REM (pREM) characterised by rapid eye movements and myoclonic twitches, and tonic REM (tREM) characterised by muscle atonia and desynchronised EEG. ${ }^{18}$ In healthy subjects reductions in ventilation during REM sleep are of variable extent and duration and occur particularly in relation to periods of eye movements - that is, pREM. ${ }^{12}$ Similar findings were reported in patients with COPD by George and colleagues ${ }^{19}$ who found that falls in $\mathrm{SaO}_{2}$ were closely related to the density of eye movements. They found an overall fall in ventilation during $p R E M$ sleep but the mechanism of this hypoventilation was not investigated.

Few studies of the electrical activity of the inspiratory muscles during sleep have been reported, even in normal subjects. In healthy individuals a considerable decrease in intercostal muscle activity is seen while diaphragmatic activity has been reported to be increased $^{3}$ or suppressed. ${ }^{4}$ Episodes of hypopnoea are seen particularly in association with eye movements, ${ }^{4}$ and inspiratory activity of the upper airway muscles has also been shown to be reduced in association with eye movements in normal subjects. ${ }^{5}$

In patients with COPD Hudgel et $a l^{7}$ showed that diaphragmatic EMG activity decreased in most cases during REM sleep but it increased in two of 13 patients; intercostal EMG activity decreased in the one patient in whom it was recorded. No differentiation was made between tREM and pREM sleep. Johnson $e t a l^{6}$ studied the activity of the scalene and sternomastoid muscles in patients with COPD and showed consistent reductions in EMG activity in association with pREM, but activity of other inspiratory muscles was not reported.

Despite an acclimatisation night to minimise the "first night effect", our subjects slept poorly. Others have encountered a similar problem in patients with COPD. ${ }^{20}$ We did, however, obtain good quality recordings during pREM sleep in nine of the 10 subjects. The amount of data available for analysis was further limited by restricting measurements to those obtained in a constant posture.

Surface EMG recordings have the disadvantage of reduced specificity compared with those obtained using needle electrodes. The electrode placements used were, however, chosen to reflect EMG activity of the relevant muscles with least contamination from other muscles. Moreover, previous work has shown EMG activity from transmandibular electrodes to be qualitatively similar to signals from genioglossus intramuscular electrodes, ${ }^{21}$ and surface diaphragmatic EMG recordings are qualitatively similar to signals obtained from oesophageal electrodes even during changes in lung volume. ${ }^{22}$ In patients with COPD it has been shown that the surface diaphragmatic EMG correlates well with transdiaphragmatic pressure. ${ }^{7}$ We found no evidence of abdominal muscle activity during sleep, but cutaneous electrodes are probably less sensitive for detection of expiratory activity as recent work has shown that the most frequently active expiratory muscle in awake subjects with COPD is transversus abdominis, which is the least accessible to surface recording. ${ }^{23}$ We classified as "central" those events where an overall reduction in inspiratory EMG activity alone was observed; "obstructive" events were those where abdominothoracic paradox, a large increase in $\mathrm{EMG}_{\mathrm{Ge}}$ at the termination of hypopnoea, and EEG evidence of arousal were observed in the presence of snoring. One subject (no. 4) who was categorised as having obstructive hypopnoea had no detectable abdominothoracic paradox during these events. As has been pointed out previously, this does not exclude obstructive events as no account is taken of motion in the craniocaudal dimension. ${ }^{24}$ Confident identification of these events would require measurement of oesophageal pressure which was not obtained, but the association with snoring and arousal supports the classification as "obstructive".

We have confirmed and extended previous observations on the important association between phasic eye movements during REM sleep and suppression of activity of the inspiratory muscles in patients with COPD. Our results help to explain the mechanisms of several previous observations in REM sleep - namely, hypoventilation in pREM $^{1}{ }^{1}$ reduced contribution of rib cage to ventilation, ${ }^{7}$ decrease in oxygen utilisation by the respiratory muscles, ${ }^{8}$ and oxygen desaturation in patients with COPD related to the density of eye movements. ${ }^{18}$ The limited data available from this and other studies suggest that the inhibitory effects of pREM sleep in patients with COPD and normal subjects are similar. The consequences for oxygenation, however, are likely to be greater in patients with COPD, particularly in those of the "blue bloater" type who show more marked arterial desaturation during sleep. ${ }^{25}$

\section{MECHANISMS OF HYPOPNOEA}

The relative degrees of inhibition of the various inspiratory muscle groups during pREM sleep varied between individuals, but the pattern was consistent within an individual, as has also been observed in normal subjects by Neilly et al. ${ }^{26}$ Intercostal muscle activity was proportionally more suppressed than that of the diaphragm in all but one of our subjects. The degree of reduction in $\mathrm{EMG}_{\mathrm{Ge}}$ was more variable than that of $E M G_{\text {Int }}$ or $E M G_{D i}$. The differential suppression of inspiratory muscle groups associated with pREM sleep has clear im- 
plications for the mechanism(s) of hypopnoea and consequent oxygen desaturation. In all cases in the present study such events were characterised by hypopnoea rather than complete apnoea. Of the nine subjects studied in pREM sleep, the pattern of hypopnoea was classified as "central" in five and "obstructive" in four. A study of patients with the sleep apnoea syndrome suggested that an important determination of whether an event is classified as "central" or "obstructive" is the balance of activity between the upper airway muscles and the inspiratory "pump" muscles. ${ }^{27}$ A similar balance may be relevant to the genesis of hypopnoeas in some patients with COPD. Thus, overall reduction in activity of the various inspiratory muscles (fig 3, right) results in a "central" hypopnoea whilst disproportionate reduction in $\mathrm{EMG}_{\mathrm{Ge}}$ activity produces an "obstructive" hypopnoea even though activity of other inspiratory muscles is also reduced (fig 4 , right). However, greater reduction in peak activity of the upper airway muscles than in that of the inspiratory "pump" muscles during pREM sleep was seen in only one of the subjects (no. 1). Clearly, upper airway anatomy and compliance also contribute to the pathogenesis of narrowing or collapse of the airway, and hence to whether or not an hypopnoea (or apnoea) appears "obstructive" or "central". The calibre of the upper airway is reduced in some subjects with COPD, ${ }^{27}$ and alcohol consumption has been suggested as a contributory factor to obstructive events in these patients. ${ }^{28}$ We did not obtain a complete alcohol history in all our subjects, but subject no. 1 was a non-drinker and none of the subjects drank alcohol within 24 hours of the study. The pattern of hypopnoea between individuals was not related to the posture in which each was studied.

Guilleminault et $a l^{9}$ suggested that desaturation in patients with COPD was commonly due to obstructive apnoea but the study population was highly selected. Subsequently, a prospective study of patients with COPD by Catterall and colleagues ${ }^{10}$ concluded that REM-related desaturation in COPD was not due to obstructive sleep apnoea. Although they noted frequent periods of hypopnoea, the mechanism was not investigated. It is, however, now accepted that the full blown clinical picture associated with the obstructive sleep apnoea syndrome can result from frequent obstructive hypopnoea without complete airway occlusion. ${ }^{11}$ Although apnoea may be infrequent in patients with COPD, our data suggest that obstructive hypopnoea may be quite common. This conclusion is also supported by the study by Littner et $a l^{29}$ which suggested that unexpected partial upper airway obstruction, as assessed by intrathoracic pressure measurement, contributed to nocturnal desaturation in three of nine patients with COPD.

\section{DISCOORDINATE CHEST WALL MOTION}

Reduced expansion and, occasionally, paradoxical motion of the rib cage during REM sleep have been described in previous studies in patients with COPD and related to inhibition of respiratory muscle EMG activity, ${ }^{67}$ but the studies concentrated on volume changes of the rib cage compartment as a whole rather than motion in a particular dimension. Seven patients studied by Hudgel et $a l^{7}$ showed paradoxical motion of the rib cage compartment during REM sleep, with five exhibiting this pattern only in the hypopnoeic periods of REM sleep, but the relation to specific inspiratory muscle activity was not clear. Johnson and Remmers ${ }^{6}$ reported paradoxical motion of the rib cage compartment in association with reduced EMG activity of the scalenus anterior muscle during pREM sleep, but no data were given on intercostal or diaphragmatic activity; abdominal excursion increased but only by a small amount. Since, however, similar compartmental paradox occurs with hypoventilation due to narrowing of the upper airway, "central" and "obstructive" hypopnoea cannot be distinguished using this criterion alone. ${ }^{2}$

We are unaware of any previous studies which have assessed lateral rib cage paradox (Hoover's sign) during sleep. Although our series included only four subjects with Hoover's sign while awake, we found consistently that lateral paradox became less, rather than more, evident during pREM-related hypopnoeas. Classically, Hoover's sign is associated with a low flat diaphragm and the proposed mechanism involves abnormal traction on the lateral rib cage via its insertional effect. ${ }^{12}$ We hypothesised that loss of intercostal muscle activity and relative preservation of diaphragmatic activity during REM sleep might exaggerate the distortion, but clearly this was not the case. However, a change in magnitude of the integrated EMG activity may not be related directly to the force of muscle contraction and there is some evidence that, during REM sleep, electromechanical coupling of the diaphragm becomes less efficient. ${ }^{30}$ Such an effect might counter the greater rib cage distortion which would be expected from relatively unopposed diaphragmatic contraction. Alternatively, the degree of lateral rib cage paradox in subjects with hyperinflation may depend simply on the strength of diaphragmatic contraction, irrespective of any potential stabilising effect of intercostal muscle activity.

We thank the Chest, Heart and Stroke Association and the Breathe North branch of the British Lung Foundation for financial support for this project.

1 Gould GA, Gugger M, Molloy J, Tsara V, Shapiro CM, Douglas NJ. Breathing pattern and eye movement density during REM sleep in humans. Am Rev Respir Dis 1988; 138:874-7.

2 Millman RP, Knight H, Kline LR, Shore ET, Chung DCC, Pack AI. Changes in compartmental ventilation in association with eye movements during REM sleep. $\mathcal{F} A p p l$ Physiol 1988;65:1196-202.

3 Tabachnik E, Muller NL, Bryan AC, Levison H. Changes in ventilation and chest wall mechanics during sleep in normal adolescents. $\mathcal{F}$ Appl Physiol: Respirat Environ 1981; 51:557-64.

4 Muller NL, Francis PW, Gurwitz D, Levison, Bryan CA. Mechanism of haemoglobin desaturation during rapideye-movement sleep in normal subjects and in patients eye-movement sleep in normal subjects and in patients
with cystic fibrosis. Am Rev Respir Dis 1980;121:463-9. 5 Wiegand L, Zwillich CW, Wiegand D, White DP. Changes 
in upper airway muscle activation and ventilation during phasic REM sleep in normal men. $\mathcal{F}$ Appl Physiol 1991; 71:488-97.

6 Johnson MW, Remmers JE. Accessory muscle activity during sleep in chronic obstructive pulmonary disease. $\mathcal{F} A p p l$ Physiol: Respirat Environ 1984;57:1011-7.

7 Hudgel DW, Martin RJ, Capehart M, Johnson B, Hill P. Contribution of hypoventilation to sleep oxygen desaturation in chronic obstructive pulmonary disease. $\mathcal{F}$ Appl Physiol: Respirat Environ 1983;55:669-77.

8 Fletcher EC, Gray BA, Levin DC. Nonapneic mechanisms of arterial oxygen desaturation during rapid-eye-movement sleep. F Appl Physiol: Respirat Environ 1983;54:632-9.

9 Guilleminault C. Cummiskey J, Motta J. Chronic obstructive airways disease and sleep studies. Am Rev Respir Dis 1980;122:397-406.

10 Catterall JR, Douglas NJ, Calverley PMA, Shapiro CM, Brezinova V, Brash HM, et al. Transient hypoxaemia during sleep in chronic obstructive airways is not a sleep during sleep in chronic obstructive airways is not a slepp

11 Gould GA, Whyte KF, Rhind GB, Airlie MAA, Catterall JR, Shapiro CM, et al. The sleep hypopnoea syndrome. Am Rev Respir Dis 1988;137:895-900.

12 Gilmartin JJ, Gibson GJ. Mechanisms of paradoxical rib cage motion in parents with chronic obstructive pulmonary disease. Am Rev Respir Dis 1986;134:683-7.

13 Griffiths CJ, Gilmartin JJ, Gibson GJ, Murray A. Measurement of chest wall movement; design, performance and clinical use of a four channel magnetometer instrument. Clin Phys Physiol Meas 1983;4:363-71.

14 Wells DT, Allen RP, Wagman AMI. A single channel system for recording eye movements. Psychophysiology 1977;14: $73-4$

15 Griffiths CJ, Cooper BG, Gibson GJ. A video system for investigating breathing disorders during sleep. Thorax 1991;46:136-40.

16 Rechtshaffen A, Kales A, eds. A manual of standardised terminology, techniques and scoring system for sleep stages of human subjects. Bethesda, MD. National Institute of Health (Publication No. 204), 1968.

17 Drinnan MJ, Murray A, White JES, Smithson AJ, Gibson GJ, Griffiths CJ. Automated measurement of the cyclic GJ, Griffiths CJ. Automated measurement of the cyclic activity of the

18 Sullivan CE, Murphy E, Kozar LF, Phillipson EA. Ventil- atory responses to $\mathrm{CO}_{2}$ and lung inflation in tonic versus phasic REM sleep. F Appl Physiol: Respirat Environ 1979, 47:1304-10.

19 George CF, West P, Kryger MH. Oxygenation and breathing pattern during phasic and tonic REM in patients with chronic obstructive pulmonary disease. Sleep 1987;10: 234-43.

20 Leitch AG, Clancy LJ, Leggett RJE, Tweedale P, Dawson $P$, Evans JI. Arterial blood gas tensions, hydrogen ion, and electroencephalogram during sleep in patients with chronic ventilatory failure. Thorax 1976;31:730-5.

21 Sauerland EK, Sauerland BAT, Orr WC, Hairston LE. Noninvasive electromyography of human genioglossal (tongue) activity. Electromyogr Clin Neurophysiol 1981;21 279-86.

22 Benzett RB, Inbar GF, Brown R, Goldman M, Rossier A, Mead J. Diaphragm electrical activity during negative lower torso pressure in quadriplegic men. $\mathcal{f}$ Appl Physiol 1981;51:654-9.

23 Ninane V, Rypens F, Yernault J-C, de Troyer A. Abdominal muscle use during breathing in patients with chronic airflow obstruction. Am Rev Respir Dis 1992;146:15-21.

24 Staats BA, Bonekat HW, Harris CD, Offord KP. Chest wall motion in sleep apnoea. Am Rev Respir Dis 1984;130: 59-63.

25 Douglas NJ, Calverley PMA, Leggett RJE, Brash HM, Flenley DC, Brezinova V. Transient hypoxaemia during sleep in chronic bronchitis and emphysema. Lancet 1979; i: $1-4$.

26 Neilly JB, Gaipa EA, Maislin G, Pack AI. Ventilation in early and late rapid-eye-movement sleep in normal humans. $\mathcal{F}$ Appl Physiol 1991;71:1201-15.

27 Block AJ, Faulkner JA, Hughes RL, Remmers JE, Thach B. Factors influencing upper airway closure. Chest 1984; 86:114-22.

28 Chan CS, Grunstein RR, Bye PTP, Woolcock AT, Sullivan CE. Obstructive sleep apnoea with severe chronic airflow limitation. Am Rev Respir Dis 1989;140:1274-8.

29 Littner MR, McGinty DJ, Arand DL. Determinants of oxygen desaturation in the course of ventilation during sleep in chronic obstructive pulmonary disease. Am Rev Sleep in chronic obstructive pul

30 Hendricks JC, Kline LR. Differential activation within costal diaphragm during rapid-eye-movement sleep in cats. $\mathcal{f}$ Appl Physiol 1991;70:1194-200. 